\title{
Matrix Metalloproteinase-9 (MMP-9) Level in Tuberculosis Exposed and Infected Children
}

\author{
Wildana Azikin, Amiruddin Laompo, Husein Albar, Dasril Daud \\ Department of Pediatrics, Medical Faculty of Hasanuddin University, Makassar, South Sulawesi, Indonesia
}

Email address:

wildanaazikin@yahoo.co.id (W. Azikin)

\section{To cite this article:}

Wildana Azikin, Amiruddin Laompo, Husein Albar, Dasril Daud. Matrix Metalloproteinase-9 (MMP-9) Level in Tuberculosis Exposed and Infected Children. American Journal of Health Research. Vol. 5, No. 1, 2017, pp. 7-10. doi: 10.11648/j.ajhr.20170501.12

Received: January 24, 2016; Accepted: February 4, 2016 Published: February 15, 2017

\begin{abstract}
Background: Lung Tuberculosis (TB) is a chronic infectious disease caused by Mycobacterium tuberculosis (M. $\mathrm{Tb}$ ). Excessive body's immune response to $\mathrm{M}$. Tb will contribute to the host tissue damage. $\mathrm{M}$. Tb infection stimulates gene expression and MMP-9 secretion from monocyte which is infected by M. Tb. M. Tb molecular mechanisms inducing granuloma formation which is the ESAT-6 protein that stimulates the production of matrix metalloproteinase-9 (MMP-9) from epithelial cells near the infected macrophages. Objective: To evaluate the levels of Matrix Metalloproteinase-9 (MMP-9) in children who lived in the same house with a tuberculosis person. Methods: A cross sectional study was conducted at the Lung Health Community Center (BBKPM) Makassar, from May to July 2015. The study population was children aged 3 months to 18 years. Results: Levels of MMP-9 were examined in 55 samples of the study, 29 samples infected with TB (52.7\%), and 26 samples exposed to TB (47.3\%). There is no significant difference in the levels of MMP-9 and genders, age, nutritional status, status of BCG, as well as the levels of MMP-9 in the group of exposed and infected to TB ( $p>0.05)$. Conclusion: There was no significant differences between the levels of MMP-9 in the group of exposed and infected to TB.
\end{abstract}

Keywords: Matrix Metalloproteinase-9 (MMP-9), Tuberculosis Exposed Children, Tuberculosis Infected Children

\section{Introduction}

Tuberculosis (TB) is a chronic infectious disease caused by Mycobacterium tuberculosis (M. Tb). Indonesia still ranks to 5 countries with the highest TB patients in the world, so that the current TB still remains a health problem and even more dangerous, so it is called the re-emerging disease. [1]

TB disease is the second leading cause of death from infectious disease in the whole world. Estimates in 2012 approximately 8.6 million cases of TB and 1.3 million of them died. Approximately 530.000 cases of TB children with 74.000 of them died. [2]

The total number of TB cases in a child of 7 Hospital Centre for Education in Indonesia for 5 years (1998-2002) is 1086 persons with TB with a mortality rate that varies from $0 \%-14.1 \%$. The largest age group was 12-60 months (42.9\%), whereas for infants $<12$ months gained $16.5 \%$. In 2009 the number of TB cases of child reaches 30.806 including 1.865 smear-positive cases. Proportion of TB cases children of all TB cases reached 10: 45\%. [1]

Excessive body's immune response to Mycobacterium tuberculosis will contribute to damage the host tissues, but the mechanisms involved have not known with certainty and it is a multifactorial process. [3] Matrix metalloproteinase (MMP) is a structure associated with zinc-containing enzymes that degrade extracellular matrix. [4] MMP-9 in quantity is the most important of several MMP and it is secreted by monocytes and macrophages and is vital for this response. [5] Matrix Metalloproteinase-9 (MMP-9) is an enzyme capable of degrading the various components of the extracellular matrix, mainly secreted by fibroblasts, endothelial cells, polymorph nuclear cells, keratinocytes, and macrophages. The increased expression of MMP-9 occurred in the process of inflammation and malignancy. [6]

Most individuals who are infected with mycobacterium tuberculosis (M. Tb) will develop into a latent infection, it's happening because macrophages infected attract immune cells to form granulomas, to secrete cytokines such as TNF$\alpha$, IL-1b, which stimulates monocytes, endothelial cells, cells fibroblasts for the secretion of MMP-9 [6], and then isolating the bacteria and prevent the spread of. [7]

According to Shiryaev et al. study, they explained that the 
infection of $\mathrm{M}$. Tb stimulate the gene expression and secretion of MMP-9 monocytes cells infected by M. Tb. [8] Yong Li et al. discovered the molecular mechanism of $\mathrm{M}$. Tb induces granuloma formation that is the ESAT-6 protein that stimulates the production of MMP-9 from epithelial cells near the infected macrophages. [8,9] The expression of MMP-9 is seems at the early development of granulation and during the necrosis. It was found that the concentration of MMP-9 in patients with granuloma (Median $108 \mathrm{pg} / \mathrm{ml}$ ) was higher than without granuloma (Median $43 \mathrm{pg} / \mathrm{ml}$ ). [10] Under these conditions it is important to do a study to determine the levels of MMP-9 against children exposed to and infected with mycobacterium tuberculosis. The purpose of this study was to determine the levels of matrix metalloproteinase-9 (MMP-9) household contacts of children with tuberculosis.

\section{Materials and Methods}

This study was conducted at Lung Health Community Center (BBKPM) in Makassar from May until July 2015 exclusively. The study population was children aged 3 months to 18 years with a history of household contact with positive adult TB patient The study sample is all the eligible population met the inclusion and exclusion criteria of study. The inclusion criteria are children ages 3 month up to 18 years and children who lived in the same house with a tuberculosis person, while the exclusion criteria are children with $\mathrm{TB}$, children with a poor nutritional status or has an immunocompromised disease, and children with long-term use of steroids or other immunosuppressants.

This study was approved by the Ethics and Industry Research Committee of the hospital and Medical Faculty of Hasanuddin University. Written informed consent was obtained from the patients' parents or legal guardian following full and detail explanation regarding the study's protocol. All the eligible patients are noted: name, age, sex, nutritional status, history of BCG immunization (BCG scar). Nutritional status is determined based on body weight for height according to NCHS and WHO standards. Then the patients do the physical examination, laboratory, radiology and tuberculin test. Based on the tuberculin test results are grouped into two groups: exposed and infected with TB. Then we examined the levels of MMP-9 and analyzing the levels of MMP-9 in both groups. The data obtained are grouped by its type of data into groups of exposed and infected with TB, and then each was analyzed in accordance with appropriate statistical methods, the analyses of univariate and bivariate.

\section{Results}

Table 1 shows the characteristics of the sample assessed such as the sex, age, nutritional status, status of tuberculosis, BCG status and levels of MMP-9. For the category of sex, the male group consisted of 28 samples (51\%) and 27 female (49\%). In the age group obtained a median of 5.9 with a range of 0.75 to 15 , mean 6.18 and standard deviations of 3.9. In the nutritional status group, poor child group consisted of 31 samples $(56.4 \%)$, moderate-nourished children group with 20 samples (36.4\%), and overweight of 4 samples (7.3\%). For the category of tuberculosis status groups, group of children infected with TB is 29 samples $(52.7 \%)$ and exposed to TB is 26 samples $(47.3 \%)$. In the category of BCG status, the group of children with BCG positive (BCG vaccination) is composed of 45 samples $(81.8 \%)$, and $B C G$ negative (which does not get vaccinated of BCG) is 10 samples (18.2\%). The levels of MMP-9 with a median 2.95, range from 0.14 to 41.77 , mean 5.08 and 6.33 of standard deviations.

Table 1. Study sample characteristics.

\begin{tabular}{lll}
\hline No. & Sample characteristics & Total $(\mathbf{n}=\mathbf{5 5})$ \\
\hline 1. & Sex & $28: 27(51: 49)$ \\
& Male: Female (\%) & \\
2. & Age (year) & $5.9(0.75-15)$ \\
& Median (Range) & $6.18(3.99)$ \\
& Mean (SD) & \\
3. & Nutritional status & $31: 20: 4(56.4: 36.4: 7.3)$ \\
& Poor: Moderate: Overweight $(\%)$ & $29: 26(52.7: 47.3)$ \\
4 & Tuberculosis status & \\
5 & Infected: Exposed to TB (\%) & $45: 10(81.8: 18.2)$ \\
& BCG status & \\
6 & Positive: Negative & MMP-9 levels (ng/ml) \\
& Median (Range) & $2.95(0.14-41.77)$ \\
& Mean (SD) & $5.08(6.33)$ \\
& Total: & $55(100 \%)$ \\
\hline
\end{tabular}

Table 2. Comparison of the MMP-9 levels according to sex.

\begin{tabular}{lll}
\hline \multirow{2}{*}{ MMP-9 levels (ng/ml) } & Sex & \\
\cline { 2 - 3 } & Male $(\mathbf{n}=\mathbf{2 8})$ & Female $(\mathbf{n}=\mathbf{2 7})$ \\
\hline Mean & 4.72 & 5.46 \\
Median & 2.83 & 3 \\
Standard deviation & 4.74 & 7.27 \\
Range & $0.66-20.96$ & $0.14-41.77$ \\
Uji Mann Whitney & & $p=0.419(p>0.05)$ \\
\hline
\end{tabular}

The group of male median levels of MMP-9 is at 2.83 $\mathrm{ng} / \mathrm{ml}$, whereas in the group of female, with median levels of MMP-9 at $3 \mathrm{ng} / \mathrm{ml}$. No significant differences in the levels of MMP-9 between male and female with a $p>0.05$. (Table 2)

Table 3. Comparison of the MMP-9 levels according to age.

\begin{tabular}{lll}
\hline \multirow{2}{*}{ MMP-9 levels (ng/ml) } & Age & \\
\cline { 2 - 3 } & Less than or equal to 5 years & Over 5 years \\
\hline Mean & 6.25 & 4.1 \\
Median & 3.78 & 2.42 \\
Standard deviation & 8.04 & 4.35 \\
Range & $1.35-41.77$ & $0.14-20.96$ \\
Uji Mann Whitney & & $p=0.105(p>0.05)$ \\
\hline
\end{tabular}

In Table 3, it can be seen that the group of children less than or equal to 5 years, their median levels of MMP-9 at $3.78 \mathrm{ng} / \mathrm{ml}$, whereas in over 5 years, a median levels of MMP-9 at $2.42 \mathrm{ng} / \mathrm{ml}$. Statistical analyses showed no 
significant differences in the levels of MMP-9 among children aged less than or equal to 5 years and children aged over 5 years, $\mathrm{p}>0.05$.

Table 4. Comparison of the MMP-9 levels according to nutritional status.

\begin{tabular}{llll}
\hline \multirow{2}{*}{ MMP-9 levels (ng/ml) } & \multicolumn{3}{l}{ Nutritional status } \\
\cline { 2 - 4 } & Poor & Well nutrition & Overweight \\
\hline Mean & 4.53 & 6.43 & 2.58 \\
Median & 3.69 & 2.97 & 2.62 \\
Standard deviation & 3.53 & 9.5 & 1.19 \\
Range & $0.14-15.45$ & $1.14-41.77$ & $1.10-3.99$ \\
Uji Mann Whitney & \multicolumn{3}{l}{$p=0.700(p>0.05)$} \\
\hline
\end{tabular}

Table 4 show in the group of poor children, the median levels of MMP-9 at $3.69 \mathrm{ng} / \mathrm{ml}$; whereas in the group of wellnourished children, the median levels of MMP-9 by 2.97 $\mathrm{ng} / \mathrm{ml}$; and in the group of overweight children, the median levels of MMP-9 of $2.62 \mathrm{ng} / \mathrm{ml}$. Statistical analyses no significant difference between the levels of MMP-9 and nutritional status, $\mathrm{p}>0.05$.

Table 5. Comparison of the MMP-9 levels according to BCG status.

\begin{tabular}{lll}
\hline \multirow{2}{*}{ MMP-9 levels (ng/ml) } & BCG & \\
\cline { 2 - 3 } & Yes & No \\
\hline Mean & 5.56 & 2.95 \\
Median & 3.55 & 2.19 \\
Standard deviation & 6.88 & 1.6 \\
Range & $0.14-41.77$ & $1.63-5.98$ \\
Uji Mann Whitney & $p=0.226(p>0.05)$ \\
\hline
\end{tabular}

It can be seen that in the group that receiving the $\mathrm{BCG}$ vaccination, the median levels of MMP-9 is $3.55 \mathrm{ng} / \mathrm{ml}$, whereas in the group that did not receive the BCG vaccination, the median levels of MMP-9 at $2.19 \mathrm{ng} / \mathrm{ml}$. Statistical analyses showed no significant difference between the levels of MMP-9 and the BCG status, $p>0.05$. (Table 5)

Table 6. Comparison of the MMP-9 levels exposed and infected with TB.

\begin{tabular}{|c|c|c|c|}
\hline \multirow{3}{*}{ MMP-9 levels (ng/ml) } & \multicolumn{2}{|c|}{ Tuberculosis status } & \multirow{3}{*}{ p value } \\
\hline & Infected TB & Exposed to TB & \\
\hline & $(n=29)$ & $(n=26)$ & \\
\hline Mean & 6.08 & 3.97 & \multirow[t]{4}{*}{0.673} \\
\hline Median & 3.49 & 2.91 & \\
\hline Standard deviation & 8.26 & 2.78 & \\
\hline Range & $0.66-41.77$ & $0.14-11.29$ & \\
\hline Uji MannWhitney & & & $(p>0.05)$ \\
\hline
\end{tabular}

The group infected with TB, their median levels of MMP9 at $3.49 \mathrm{ng} / \mathrm{ml}$, whereas in the group exposed to $\mathrm{TB}$, the median levels of MMP-9 by $2.91 \mathrm{ng} / \mathrm{ml}$. Mann-Whitney test showed no significant difference between the levels of MMP9 infected and exposed to TB, $p>0.05$. (Table 6)

\section{Discussion}

We uses a cross-sectional design to determine the role of the levels of MMP-9 against children exposed to and infected with TB, conducted from May until July 2015. We obtained 55 samples of household contact with adult patients, divided into 2 groups, 29 samples infected with TB (52.7\%) and 26 samples exposed to TB (47.3\%). Comparison of the MMP-9 levels according to the sex, age, nutritional status, BCG status and the status of TB (infected and exposed to TB) for further analyses.

Comparison between the levels of MMP-9 and sex showed no significant difference which is in line with the results of study by Yurdakul et al. in Turkey that there is no significant difference between the expression of MMP-9 and sex, with $p>0.05$. [11] On the contrarily, the research by Snitker et al. in Pennsylvania and Sundstrom et al. at Framingham that the levels of MMP-9 was higher in male than female with a $p$ value of 0.008 and 0.03 . [12, 13] This is presumably because of the role of estrogens is protective. Besides, those neutrophils are able to reduce the levels of MMP-9 during the period of menstruation when estrogens levels are higher.

The analyses of the comparison of the levels of MMP-9 and age showed no significant difference with a $\mathrm{p}$ value of 0.105 . This is same with the research by Kilic et al. in Turkey showed no significant difference between the levels of MMP9 in the age group with a value of $p>0.05$. [14] Research by Lee et al. in Korea showed that there was no significant difference between the expression levels of MMP-9 age group, with a $\mathrm{p}$ value 0.820 . [15]

The analyses of the comparison between the levels of MMP-9 and nutritional status showed no significant difference ( $p$ value of 0.70 ). This is similar with a study by Lacerda et al. in Brazil who studied drug resistance to hypertension, there is no difference in the levels of MMP-9 and nutritional status [16], but not in accordance with the study by Olszewska et al. which examines the levels MMP-9 against child and adolescent obesity, it was found that the levels of MMP-9 was higher in obese children compared with the control group (well nutrition) with a $\mathrm{p}$ value of 0.02 . [17]

The analyses of the comparison between the levels of MMP-9 and BCG status showed no significant difference with a $\mathrm{p}$ value of 0.226 , but with a median value that is higher in children who received the BCG vaccination that is 3.55. From previous study by Jarbrink et al. in animals suggest of mycobacterium bovis (BCG) infection causes an increase in MMP-9 activity of macrophages, both in vitro and in vivo. [18]

On this study, the median levels of MMP-9 in the infected group were higher than the group exposed to $\mathrm{TB}$, but no significant difference with $\mathrm{p}$ value $0.673(\mathrm{p}>0.05)$.

Sheen et al. showed that the levels of MMP-9 were higher in pleural fluid from tuberculosis as compared with the control group (malignant effusions and transudates in heart failure) $(p<0.001)$. [9] In vivo study by Price et al. revealed that the levels of MMP-9 in the cerebrospinal fluid (CSF) of patients with TB meningitis higher (median (range), 3.19 (0.19--31.00) $\mathrm{ng} / \mathrm{ml} /$ cell) compared with meningitis bacteria (0.23 (0: 01 to $18: 37) \mathrm{ng} / \mathrm{ml} /$ cell), viral meningitis $(0.20$ $(0.04--31.00) \mathrm{ng} / \mathrm{ml} / \mathrm{cell})$ with a value of $\mathrm{p}<0.01$. (10)

Our study revealed the median (range) levels of MMP-9 in the infected group $(3.49(0.66-41.77))$ is higher than the unexposed group $(2.91(0.14$ to 11.29$))$, this is maybe 
because of the related to the function of MMP-9 as proteolysis local to the matrix of extracellular so that the levels of MMP-9 were measured in circulation did not differ significantly in both groups and the natural specific inhibitor of MMP-9 which is the TIMP (tissue inhibitor of metalloproteinase), that will increase rapidly in an attempt to restore normal physiological functions of the body. [19, 20] Then, increased expression of MMP-9 also occurs in the inflammatory process in general. Alveolar macrophages, neutrophils and epithelial cells to produce ROS (reactive oxygen species), and protease as a response to inflammation, which can be caused by a viral infection, mycoplasma nor due to environmental irritants and in the group exposed to TB is characterized by a negative tuberculin, while the group infected with TB is characterized by a positive tuberculin. [21]

We concluded that the levels of MMP-9 maybe not influenced by sex, age, nutritional status, and the status of BCG immunization. There is no significant difference between the levels of MMP-9 in the group of infected and exposed to TB. Multicenter prospective cohort study with a larger sample size and the levels of MMP-9 by prolonged contact with the child for adult patients with TB were need for further analyses.

\section{References}

[1] Rahajoe, N. N., Basir, D., Makmuri, M. S., Kartasasmita, C. B. Pedoman Nasional Tuberkulosis Anak. Edisi Revisi. Jakarta: UKK Respirologi PP Ikatan Dokter Anak Indonesia. 2010 .

[2] World Health Organization. Global tuberculosis report. Available from: URL: http://www.who.int/gtb/publications/globrep. 2013

[3] Danneberg, A. M. Jr. Roles of Cytotoxic Delayed-Type Hypersensitivity and Macrophage-Activating Cell-Mediated Immunity in the Pathogenesis of Tuberculosis, Immunopathology. 1994.

[4] Rundhaug, J. E. Matrix metalloproteinase, Angiogenesis and Cancer. Clinicancerres. 9: 551-554. 2003.

[5] Welgus, H. G., Campbell E. J., Cury, J. D., Eisen, A. Z., Senior, R. M., Wilhelm, S. M., Goldberg, G. I. Neutral Metalloproteinase Produced by Human Mononuclear Phagocytes. Enzyme Profile, Regulation, and Expression during Cellular Development. J. Clin. Invest. The American Society for Clinical Investigation, Inc. 1990.

[6] Stuelten CH., Byfield SD., Arany PR., Karpova TS., Stevenson W. G. S., Roberts A. B. Breast cancer cells induce stromal fibroblast to express MMP-9 via secretion of TNF- $\alpha$ and TGF- $\beta$. Journal of cell science 118. 2143-2153. 2005.

[7] Ehlers, S., Schaible, U. E. The granuloma in tuberculosis: dynamics of a host-pathogen collusion. Available at. www.frontiersin.org. 2013.

[8] Shiryaev SA., Cieplak P., Aleshin AE., Sun Q., Zhu W.,
Motamedchaboki K., Sloutsky A., Strongin AY. Matrix metalloproteinase proteolysis of the mycobacterial HSP65 protein as a potential source of immunogenic peptides in human tuberculosis. FEBS Journal, 278: 3277-3286. 2011.

[9] Yong Li., Wang Y., Liu X. The role of airway epithelial cells in response to mycobacteria infection. Clinical and developmental immunology. 2012.

[10] Sheen, S., O'Kane, C. M., Chaudhary, K., Tovar, M., Santillan, C., Sosa, J., Caviedes, L., et al. High MMP-9 activity characterises pleural tuberculosis correlating with granuloma formation. Eur Respir J. 2009; 33: 134-141.

[11] Yurdakul A., Akyurek N., Yilmaz S., Karakaya J., Memis L., Oxturk C. Prognostic impact of matrix metalloproteinases (MMP-9 and MMP-2) and vascular endothelial growth factor expression in non small cell lung cancer. Turk J Med Sci; 42 (2): 281-288. 2012.

[12] Snitker S., Xie K., Ryan KA., Yu D., Shuldiner AR., Mitchell BD., Gong DW. Correlation of circulating MMP-9 with white blood cell count in humans: Effect of smoking. Divisions of endocrinology. Volume 8 (6). 2013.

[13] Sundstrom J., Evans JC., Benjamin EJ., Lew D., Larson MG., Sawyer DB., Siwik DA., Colucci WS., Sutherland P., Wilson PW., Vasan RS. Relation of plasma matrix metalloproteinase-9 to clinial cardiovaskular risk factors and echocardiographic left ventrikular measures: 109: 2850-2856). 2004.

[14] Kilic Z., Ucar B., Ozdemir G., Colak O., Bal C., Ertugrul T. Circulating matrix metalloproteinases and tissue inhibitors of metalloproteinase levels in pediatrics patients with congenital heart disease: relationship to cardiac functions. Anadolu Kardiyol Derg: 14: 531-41. 2014.

[15] Lee CY., Shim HS., Lee S., Lee JG., Kim DJ., Chung KY. Prognostic effect of matrix metalloproteinase- 9 in patients with resected non small cell lung cancer. Journal of cardiothoracic surgery 10; 44. 2015.

[16] Lacerda L. Faria APD., Fontana V., Moreno H., Sandrim V. Role of MMP-2 and MMP-9 in resistance to drug therapy in patients with resistant hypertension. 2015.

[17] Olszewska G., M Urban. Elevated matrix metalloproteinase 9 and tissue inhibitor of metalloproteinase 1 in obese children and adolescents. 56 (6): 799-805. 2007.

[18] Jarbrink MQ., Smith DA., Bancroft GJ. Production of matrix metalloproteinases in response to mycobacterial infection. Infection and immunity. Vol 69 no 9. p. 5661-5670. 2001.

[19] Price NM. Farrar J., Chau T T H., Mai N. T. H. M. Hien T. T., Friedland J. S., Identification of a Matrix-Degrading Phenotype in Human Tuberculosis In Vitro and In Vivo. J Immunol, 166: 4223-4230. 2001.

[20] Tshesche H., Knauper V., Kramer S., Michaelis J., Oberhoff R., Reinke H. Latent collagenase and gelatinase from human neutrophils and their activation. Matrix Suppl, 1: 245-255. 1992.

[21] Voraphani N., Khongphatthanayothin A., Srikaew K., Tontulawat P., Poovorawan Y. Matrix Metalloproteinase-9 in children with dengue virus infection. Jpn. J. Infect. Dis, 63: 346-348. 2010. 